\title{
Wrinkling Prevention Methods for Sandwich Panel Structure*
}

\author{
Koichiro DAHARA**, Kazuya SANMARU**, Toshihiro YANO** \\ and Hiroshi NOGUCHI*** \\ **Yano Special Purpose Vehicle Co., Ltd, \\ Kaminofu Shingu-machi Kasuya-gun, Fukuoka, 811-0117 Japan \\ E-mail: k-dahara@yano-body.co.jp \\ ***Department of Mechanical Engineering , Kyushu University, \\ 744 Moto-oka, Nishi-ku, Fukuoka, 819-0395 Japan
}

\begin{abstract}
In this paper, we proposed a method for preventing the wrinkling of the facings of a sandwich panel whose outer and inner facings were at different temperatures. By using this method, the wrinkling of the outer facing of a sandwich panel structure, such as a sandwich panel refrigerator box, could be prevented. In order to prevent the facings of the structure from wrinkling, it was necessary to determine the wrinkling strength using a compressive test, and to reduce the thermal stress of the sandwich panel structure to less than the wrinkling strength. It was observed that a sandwich panel structure with slits in the facing reduced the thermal stress. In this study, we used sandwich panel containers to examine whether this proposed method could prevent a sandwich panel from wrinkling.
\end{abstract}

Key words: Composites, Sandwich Panel, Wrinkling, Thermal Stress

\section{Introduction}

In the distribution industry, a sandwich panel is used as one of the wall materials of a refrigerated container used to transport frozen products. Especially, an aluminum sandwich panel, in which the facing is an aluminum alloy and the core material is styrene, is widely adopted as the wall material of the refrigerated container. This is because of its high adiabaticity and rigidity, in addition to its beautiful appearance and lightweight. However, when the temperature difference between the inside and outside of container is large, a wrinkle is generated in the facing outside of the sandwich panel. The externals are then ruined as flaking off starts. The styrene foam is separated from the facing. There is a possibility that the separation of the styrene foam from the flaking off part may lead to breaking of the panel.

Many studies ${ }^{(1) \sim(5)}$ have reported the phenomenon of wrinkling. Hoff and Norris et al. ${ }^{(1),(2)}$ reported a theoretical formula for the wrinkling strength with the mechanical properties, the thickness of the facing and the core material as variables. However, it has not been clarified whether the wrinkle theory of sandwich panel units by Hoff et al. can be applied to the wrinkle of an actual sandwich panel refrigerated container. Moreover, it is not realistically easy to change the material and the thickness of the facing and the core material to prevent wrinkling. In this study, the wrinkle generated in the sandwich panel refrigerated container was then analyzed, and a reasonable and realistic method for preventing wrinkle generation in the sandwich panel structure was examined.

*Received 25 June, 2011 (No. T2-08-7031) Japanese Original : Trans. Jpn. Soc. Mech. Eng., Vol.75, No.751, A (2009), pp.271-278 (Received 20 Aug., 2008) [DOI: 10.1299/jmmp.6.106]

Copyright $\odot 2012$ by JSME 
2. Wrinkling phenomenon in aluminum sandwich panel refrigerated container and consideration

\subsection{Wrinkling phenomenon in aluminum sandwich panel refrigerated container}

The phenomenon of wrinkling on the side of an aluminum sandwich panel refrigerated container (henceforth refrigerated container) is sometimes observed, as shown in Fig.1.

For instance, there is a sandwich panel in which the facing is an A5000 aluminum alloy and the core material is polystyrene. Figures 2 shows the size and appearance of the sandwich panel refrigerated car. The structure of the refrigerated container, the sandwich panel used for the sidewall material, and a section of the sandwich panel on which the wrinkle was generated are shown in Figs. 3, 4 and 5, respectively. The features of the wrinkling are as follows.

1. Only one wrinkle is generated perpendicular to the length direction of the sandwich panel.

2. The wrinkle is generated only on the outside facing.

3. The facing peels off the core material in the wrinkled region.

There are two types of buckling models for a sandwich panel; one is the Euler type in which the entire sandwich panel is buckled, and the other is the wrinkling type ${ }^{(3)}$ in which only the facing is buckled. As seen in Figs. 1 and 5, the wrinkle on the sandwich panel of the refrigerated container is not due to the buckling of the entire panel, but due to the wrinkling phenomenon.

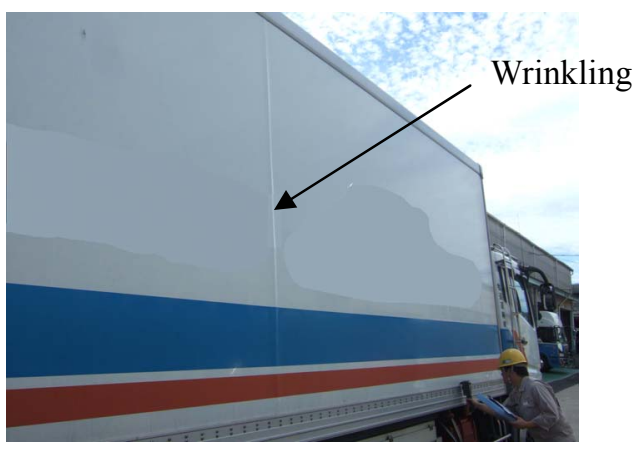

Fig. 1 Wrinkling of refrigerated container.
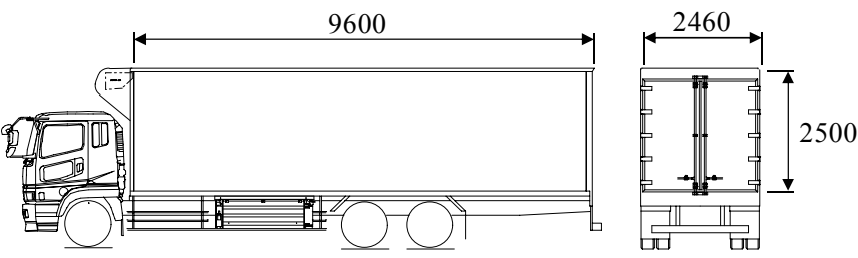

Fig. 2 Refrigerated container.

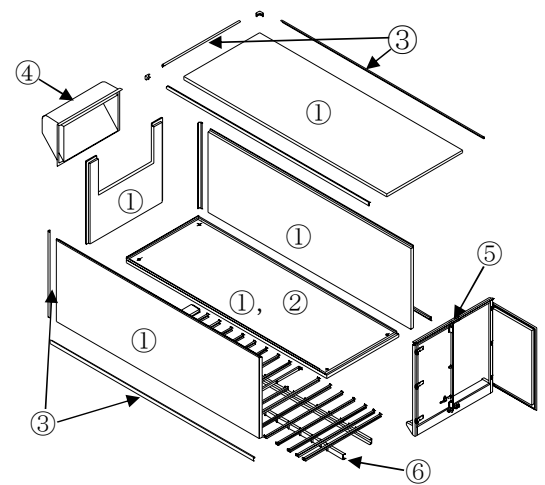

Fig. 3 Refrigerated container. 
Table 1 Parts shown in Fig. 3.

\begin{tabular}{|c|c|}
\hline (1) & Sandwich panel \\
\hline 2 & Floor aluminum extrusion \\
\hline 3 & Aluminum extrusion \\
\hline (4) & Evaporator case \\
\hline 5 & Rear door frame \\
\hline 6 & Sub frame \\
\hline
\end{tabular}

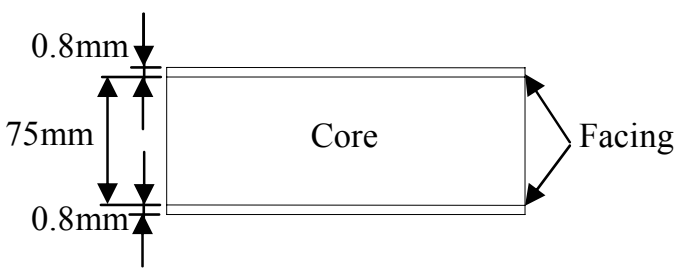

Fig. 4 Sandwich panel.

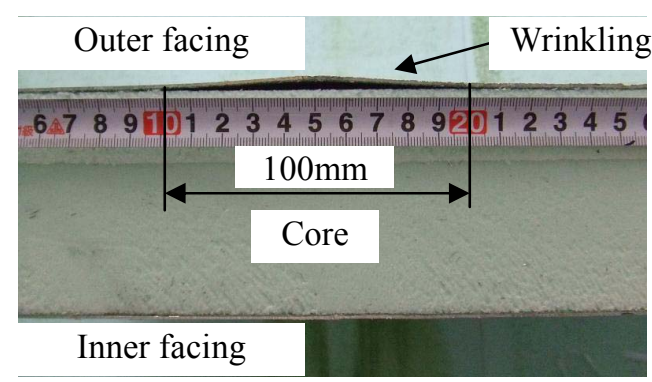

Fig. 5 Cross section of wrinkle.

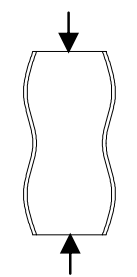

Symmetry
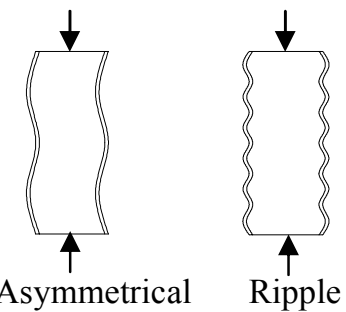

Fig. 6 Shape of wrinkling ${ }^{(3)}$.

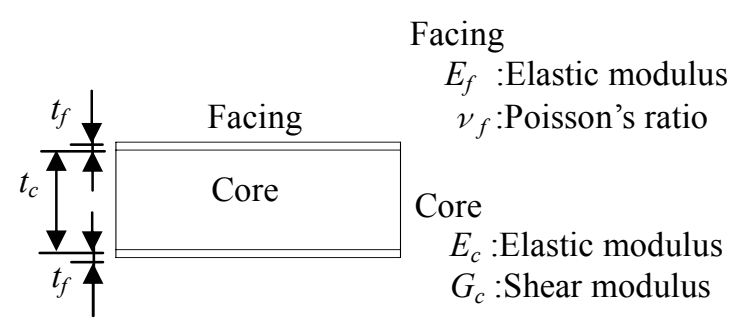

Fig. 7 Notation of sandwich panel. 


\subsection{Wrinkling}

When a sandwich panel is compressed at the edge, in the transverse direction, the facing behaves as a beam or a board supported by the elastic floor and many waves appear. As a result, the sandwich panel buckles and the phenomenon is called wrinkling. Wrinkling is generated when the rigidity of the core material is lower than that of the facing. There are three types ${ }^{(3)}$ of wrinkling shapes, namely; the symmetric type, the asymmetric type, and the ripple type. These are shown in Fig. 6.

\subsection{Theory of wrinkling strength}

Hoff and Norris et al. studied the wrinkling strength $\sigma_{c r}$. Hoff et al. reported ${ }^{(1)}$ a theoretical formula for stress in a symmetric type and the asymmetrical type of wrinkling (refer to Fig. 7) based on the strain energy theory. They expressed the wrinkling strength $\sigma_{c r}$ on the safety side by the following equation.

$$
\sigma_{c r}=\frac{1}{2} \sqrt[3]{E_{f} E_{c} G_{c}}
$$

Although the above-mentioned Hoff's theories were based on the sufficient strengths of the core material and the bond, Norris proposed ${ }^{(2)}$ a method for designing the sandwich panel by considering the facing's bending from the first stage of the compressive load when their strengths were low. The wrinkling strength is as follows according to the proposed method.

$$
\sigma_{c r}=Q_{p f} \sqrt[3]{\frac{E_{f} E_{c} G_{c}}{\left(1-v_{f}^{2}\right)}}
$$

$Q_{p f}$ can be obtained from the design diagram expressed by the parameter $K$ and the parameter $q$. Here, $q$ is given by Eq. (3) while $K$ is given by Eq. (4) which considers the degree of bending caused by an initial load.

$$
\begin{aligned}
& q=\frac{t_{c}}{t_{f}} \frac{G_{c}}{\sqrt[3]{\frac{E_{f} E_{c} G_{c}}{\left(1-v_{f}^{2}\right)}}} \\
& K=\frac{\delta}{t_{c}} \times \frac{E_{c}}{F_{g}}
\end{aligned}
$$

Here, $\delta$ is the deflection by the initial compressive load, and $F_{g}$ is the bonding strength between the facing and the core material. It is found from Eqs. (1) (4) that the wrinkling strength is independent of the length of the sandwich panel in the loading direction. This means that the wrinkling strength can be evaluated by a compressive test of the sandwich panel of an arbitrary length more than a certain length.

\subsection{Considering the wrinkle of a refrigerated container}

The wrinkle on a refrigerated container is generated by a compressive stress that exceeds the wrinkling strength in the length direction of the outside surface material. The stress generated in the facing should be less than the wrinkling strength in order to suppress the wrinkling of the structure. Therefore, measurement of the wrinkling strength of an aluminum sandwich panel used for a refrigerated container and methods for reduction of the stress in the side sandwich panel will be examined as follows.

\section{Wrinkling strength test}

The wrinkling strength of an aluminum sandwich panel used for a refrigerated container was examined. 


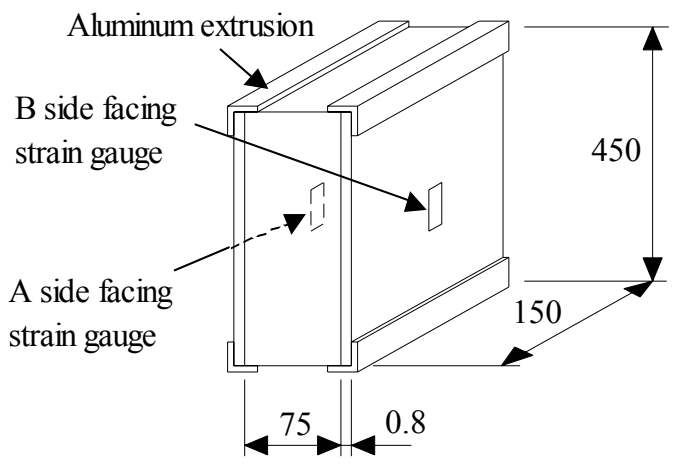

Fig. 8 Specimen for compressive test.

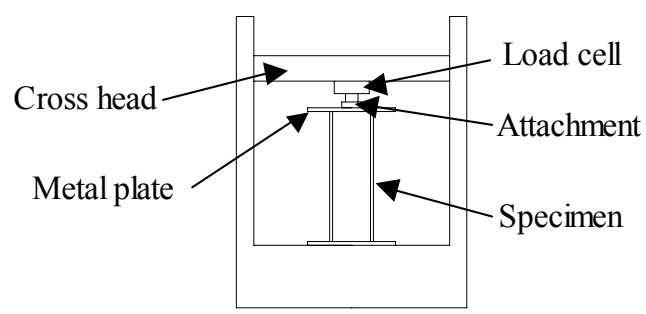

Fig. 9 Compressive test.

Table 2 Strain and stress of facing of specimens when the wrinkling occurred.

\begin{tabular}{|c|c|c|c|c|c|}
\cline { 2 - 6 } \multicolumn{1}{c|}{} & $\begin{array}{c}\text { Strain } \\
\text { of } \\
\text { A side } \\
{[\mu \varepsilon]}\end{array}$ & $\begin{array}{c}\text { Strain } \\
\text { of } \\
\text { B side } \\
{[\mu \varepsilon]}\end{array}$ & $\begin{array}{c}\text { Stress } \\
\text { of } \\
\text { A side } \\
{[\mathrm{MPa}]}\end{array}$ & $\begin{array}{c}\text { Stress } \\
\text { of } \\
\text { B side } \\
{[\mathrm{MPa}]}\end{array}$ & $\begin{array}{c}\text { Side of } \\
\text { wrinkling }\end{array}$ \\
\hline F-1 & -2039 & -2191 & -144 & -154.7 & B \\
\hline F-2 & -2600 & -1776 & -183.6 & -125.4 & A \\
\hline F-3 & -1283 & -1288 & -90.6 & -90.9 & A \\
\hline F-4 & -1764 & -1264 & -124.5 & -89.2 & A \\
\hline
\end{tabular}

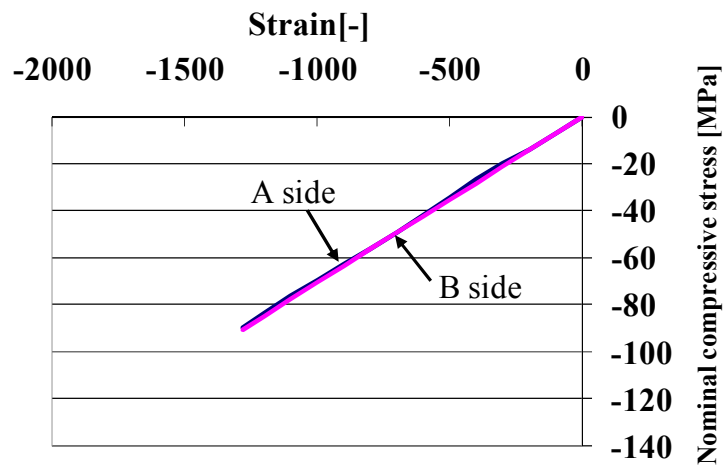

Fig. 10 Stress-strain curve of F-3.

\subsection{Wrinkling strength measurement by compressive test}

The aluminum sandwich panel was compressed, and the strain generated in the facing was measured when the wrinkling phenomenon occurred. The wrinkling strength was examined. Figure 8 shows the configuration of the test piece and Fig. 9 shows a simplified figure of the uni-axial compressive test.

Angle bars made of aluminum were bonded at the four corners of the test piece so as not to destroy the edge of the aluminum board. Single-axis strain gauges were placed on both sides of the 
facing in order to measure the strain generated. A $2 \mathrm{kN}$ load was applied before the test so that the load may evenly act on both facings. While a spacer was paved between the attachment and metallic plate in order to make the strain of each facing even. The testing machine was made by the Shimadzu Co.

It was observed that the facing waved like the ripple of Fig. 6 on either Side A or Side B of the test piece and it returned to its origin shape after unloading. When the load increased afterwards, there was sudden-destruction of the interface between the core material and the facing in the place where the wave was generated, and the strain in the surface material decreased.

Table 2 shows the strain of the facing when the destruction occurred. The stress was calculated using Hooke's law and assuming Young's modulus of the aluminum plate to be $70.6 \mathrm{GPa}$. Figure 10 shows the conventional stress-strain diagram of F-3 in Table 2. The conventional stress is a value obtained by dividing the compressive load by the sectional area of the two facings. The value for Side A facing of F-3 was the lowest strength, thus $-90.6 \mathrm{MPa}$ of F-3 was used as the wrinkling strength of the aluminum sandwich panel used for the refrigerated container.

\subsection{Comparison of wrinkling strengths by compressive test result and theoretical formula}

The wrinkling strength $\sigma_{c r}$ from the experimental results and theoretical results of Section 2.3 are as follows.

$1 \sigma_{c r}=-90.6 \mathrm{MPa}$ by the compressive test

$2 \sigma_{c r}=-131.8 \mathrm{MPa}$ by Hoff's theory

$3 \sigma_{c r}=-176.8 \mathrm{MPa}$ by Norris' theory

The experimental value is the lowest. The reason for this is that the theoretical values are based on the ideal conditions of the strength of the facing and bonding strength.

\subsection{Observation of wrinkle in specimen}

Figure 11 shows an example of the wrinkle generated in the specimen. The wavelength of the wrinkle is about $90 \mathrm{~mm}$, and it is the same as the wavelength of the wrinkle generated in an actual refrigerated container as shown in Fig. 5. It has been understood that the result does not depend on the length of the test piece as described in Section 2.3, and the wrinkling can be reproduced using a small specimen under uni-axial compression.

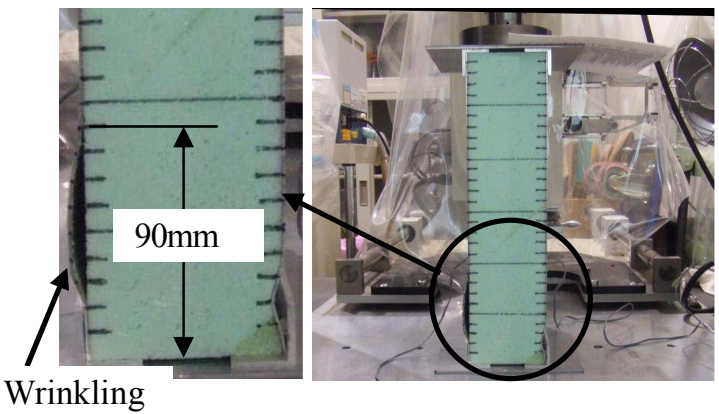

Fig. 11 Wrinkle of specimen.

4. Proposed mechanism of thermal stress generation in refrigerated container and proposed method of preventing wrinkling phenomenon

The wrinkle as shown in Fig. 1 was generated when the temperature difference between the outside and inside of the refrigerated container was large, therefore, the compressive force generated in the facing was presumed to be due to thermal stress. The generating mechanism of the thermal stress in the sandwich panel refrigerated container is then presumed, and a method for preventing the wrinkle is considered. 


\subsection{Measurement of thermal stress generated in refrigerated container}

Actually, the strain value was necessary in order to determine the stress generated in the side panel of the refrigerated container. Therefore, a single-axis strain gauge was used for the strain measurement, and 0 -balanced at $303 \mathrm{~K}$ at which there was no temperature difference between the inside and outside facings. When the temperature of the outer facing was $303 \mathrm{~K}$ and the inner one was $243 \mathrm{~K}$, the strain was measured and the stress was calculated. Figure 12 and Table 3 show the stress generated in the outside facing. According to this figure, a compressive stress was large at the center of the outside facing in the direction of the panel.

\subsection{Mechanism of generation of thermal stress in refrigerated container}

Figure 13 shows a section of the refrigerated container. The edges of the sandwich panel were connected to the aluminum molds by rivets, thus, the sandwich panel was restrained.

When the refrigerator container was cooled, the outer surface material was loaded as follows.

$\sigma_{\text {def_out }}:$ The stress nucleated in the facing as a result of the restrained deformation due to the temperature difference $\Delta T_{f}$ between the inner and outer sandwich panels. This stress ${ }^{(6) \sim(8)}$ is proportional to $\Delta T_{f}$

$\sigma_{\text {fix out }}:$ The stress nucleated in the facing as a result of the restrained deformation due to the difference $\Delta T_{\text {fix out }}$ in temperature of the sandwich panel when it was being assembled as the container and temperature of the outside facing when cooled. This stress is proportional to $\Delta T_{\text {fix } \_ \text {out }}$.

Figure 14 shows the temperature of the facing of the sandwich panel in the refrigerated container. Therefore, the thermal stress in the outside facing is expressed by Eq. (5).

$$
\sigma_{f \_ \text {out }}=\sigma_{\text {def_out }}+\sigma_{\text {fix_out }}
$$

When $C_{1}$ and $C_{2}$ are assumed to be constants, $\sigma_{\text {def_out }}$ and $\sigma_{\text {fix_out }}$ are given by the following equations.

$$
\begin{aligned}
& \sigma_{\text {def_out }}=C_{1} \times \Delta T_{f}=C_{1} \times\left(T_{\text {out }}-T_{\text {in }}\right) \\
& \sigma_{\text {fix_out }}=C_{2} \times \Delta T_{\text {fix_out }}=C_{2} \times\left(T_{\text {out }}-T_{0}\right)
\end{aligned}
$$

Equation (5) is obtained from Eqs. (6) and (7) as follows.

$$
\begin{aligned}
\sigma_{f_{-} \text {out }} & =\sigma_{\text {def_out }}+\sigma_{\text {fix_out }} \\
& =C_{1} \times \Delta T_{f}+C_{2} \times \Delta T_{f i x \_o u t} \\
& =C_{1} \times\left(T_{\text {out }}-T_{\text {in }}\right)+C_{2} \times\left(T_{\text {out }}-T_{0}\right)
\end{aligned}
$$

The parameters $C_{1}$ and $C_{2}$ are calculated with the measured temperatures inside and outside of the container and the measured strain at the point. Therefore, the stress induced by the size and shape of the container can be obtained.

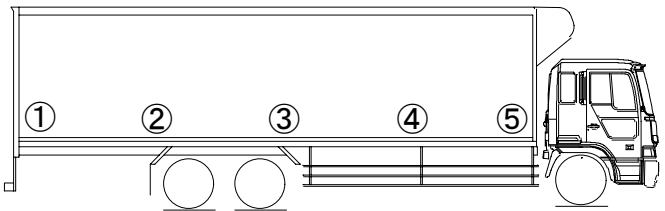

Fig. 12 Places where the strain gauges were attached on the outer facing of the refrigerated container. 
Table 3 Stresses of outer facing at refrigerating in Fig. 12.

\begin{tabular}{|c|c|c|c|c|c|}
\cline { 2 - 6 } \multicolumn{1}{c|}{} & (1) & (2) & (3) & (4) & (5) \\
\hline $\begin{array}{c}\text { Stress } \\
{[\mathrm{MPa}]}\end{array}$ & 6.0 & -61.4 & -83.3 & -59.7 & 13.0 \\
\hline
\end{tabular}
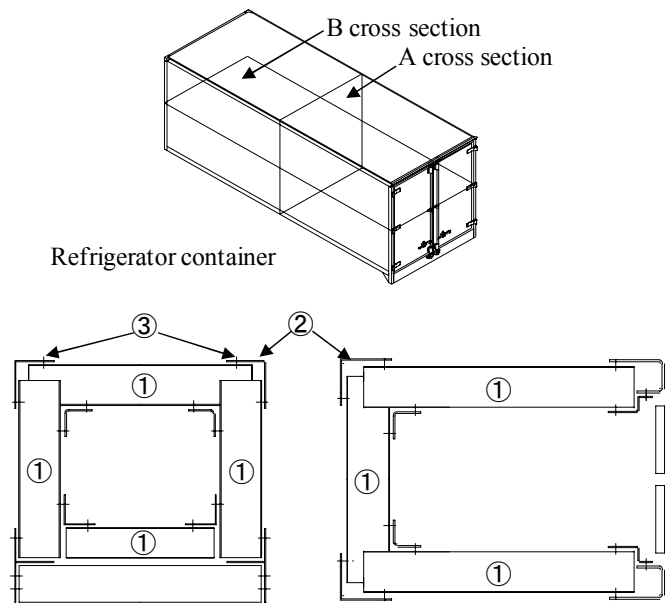

A cross section

$\mathrm{B}$ cross section

(1):Sandwich panel

(2):Alminum mold

(3):Rivet

Fig. 13 Cross section of refrigerated container.

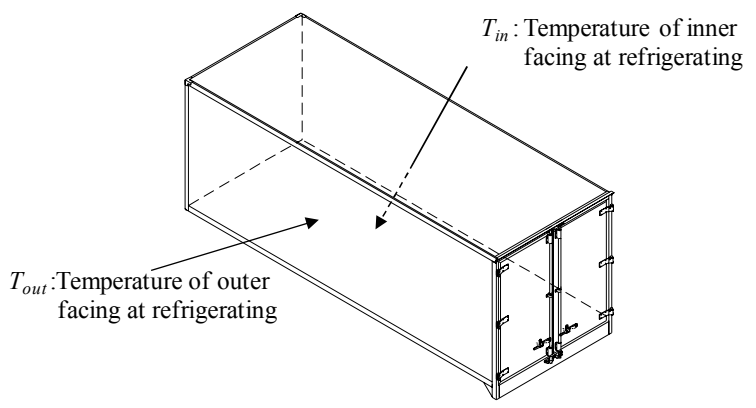

$T_{0}$ :Temperature when panels was fixed as container

Fig. 14 Temperature of facing of refrigerated container at refrigerating.

\subsection{Methods for preventing wrinkling}

Changing of the thickness or materials of the facing and the core is one of the methods of raising the winkling strength. On the other hand, it is possible to use a material with a low thermal expansion coefficient as a method of lowering the thermal stress.

Currently, It is thought that structurally decreasing the compressive stress is one of the efficient methods.

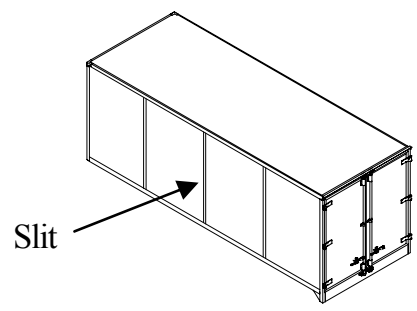

Fig. 15 Slit type sandwich panel. 


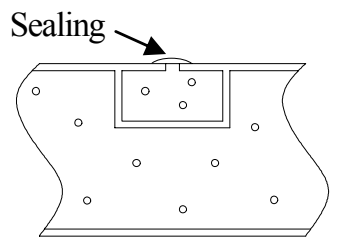

Fig. 16 Cross section of sandwich panel with slit.

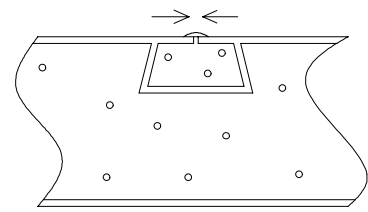

Fig. 17 Deformation of slit at refrigerating.

\subsection{Sandwich panel with slit}

To decrease the compressive stress that acts at the facing, the present authors proposed ${ }^{(9)}$ a sandwich panel structure with slits as shown in Figs. 15 and 16. It becomes difficult for the facing to be restrained in the longitudinal direction of the panel as shown in Fig.17, because the surface of the outside panel is not connected by making a structure as shown in Fig.16. The generation of $\sigma_{\text {def_out }}$ and $\sigma_{f i x \text { out }}$ that act on the surface material in Section 4.2 can be suppressed.

The method of reducing thermal stress with this type of structure is popular. However, this sandwich panel is original, because the sandwich panel is satisfied with the mechanical structure condition by connecting the facing.

\subsection{Influence of sandwich panel with slit on cold-insulation-performance and cost}

Although it was a concern that the insulated thickness became thin and the cold insulation performance decreased by introducing the slit part shown in Fig. 16, we could reduce its influence by reducing the ratio of the area of the slit part to the container surface area. Moreover, the cost of manufacturing the slit type sandwich panel could be sufficiently reduced depending on the manufacturing process compared to the cost of manufacturing of the entire refrigerated container.

\subsection{Sandwich panel with slits that prevents wrinkle generation}

The thermal stresses of the refrigerated containers using a sandwich panel without a slit and using a sandwich panel with a slit were calculated by the finite element method (FEM). The thermal stress in the sandwich panel without a slit was compared to the wrinkling strength. On the other hand, the number of slits when the generation stress was lower than the wrinkling strength of the slit-type sandwich panel was examined.

We actually manufactured the refrigerated container with each installed panel based on the FEM results and measured the generated strain. And then it was examined whether the wrinkling could be controlled in the sandwich panel with the slits. The correspondence of the generated stresses in the measured result and the FEM was finally confirmed, and the method of preventing the wrinkle was obtained.

Finally, the actual generated stress and the numerical FEM result were compared, and the method of preventing the wrinkle was discussed. 


\section{Slit type sandwich panel which can prevent wrinkling}

\subsection{Thermal stress calculation by FEM}

The refrigerated container was assumed to be a 1/2 model as in Fig. 18, and the aluminum sandwich panel was modeled as follows: the core material was divided by the first order hexahedral element and the facing was divided by the shell element. Materials other than the sandwich panel consisting of the shell element and the beam element, and parts were combined using the solid element. As the boundary conditions, the lower side of a sub-frame in Fig. 3 and Table 1 was fixed, because the face was fixed to the track. And the face cut to $1 / 2$ was restrained only the displacement in a vertical direction to the face for the symmetry condition. Table 4 shows the physical property values of the main material.

Temperature when the thermal stress was not generated and when the sandwich panel was assembled as a container was assumed to be $303 \mathrm{~K}$. The thermal stress generated in the outside surface material was calculated under the conditions listed in Table 5. That was the severest condition at which the wrinkle was generated in the container as shown in Fig. 1. The used analytical software was UGS I-DEAS.

\subsection{Comparison between numerical result and wrinkling strength}

Figure 19 shows the stress distribution in the longitudinal direction generated in the outside facing of the sandwich panel without a slit. According to the result, the wrinkling is postulated to be generated by a stress greater than the wrinkling strength under the temperature conditions listed in Table 5.

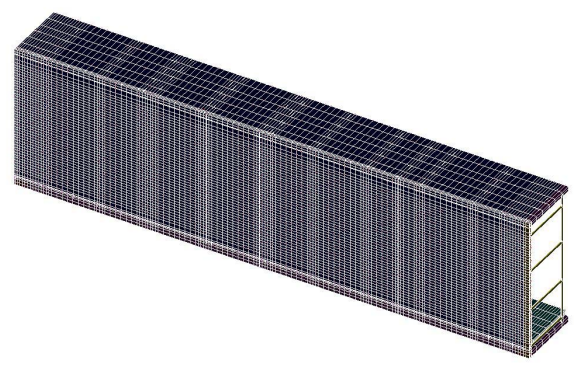

Fig. 18 FEM model of refrigerator container.

Table 4 Properties of main materials of FEM model.

\begin{tabular}{|c|c|c|}
\hline & $\begin{array}{l}\text { Facing, Extrusion } \\
\text { (Aluminum) }\end{array}$ & $\begin{array}{c}\text { Core } \\
\text { (Styrene) }\end{array}$ \\
\hline \begin{tabular}{|l} 
Elastic modulus \\
$E[\mathrm{MPa}]$
\end{tabular} & 70,600 & 27 \\
\hline \begin{tabular}{|l|} 
Poisson's ratio \\
$v$
\end{tabular} & 0.33 & 0.34 \\
\hline \begin{tabular}{|l|} 
Coefficient of thermal \\
expansion $\alpha$
\end{tabular} & $2.4 \times 10^{-5}$ & $7.3 \times 10^{-5}$ \\
\hline \begin{tabular}{|l|} 
Shear modulus \\
$G$ [MPa] \\
\end{tabular} & 26,540 & 10 \\
\hline
\end{tabular}

Table 5 The most severe condition in Fig. 1 container.

\begin{tabular}{|c|c|}
\hline $\begin{array}{c}\text { Temperature of outer facing } \\
T_{\text {out }}[\mathrm{K}]\end{array}$ & $\begin{array}{c}\text { Temperature of inner facing } \\
T_{\text {in }}[\mathrm{K}]\end{array}$ \\
\hline 333 & 243 \\
\hline
\end{tabular}




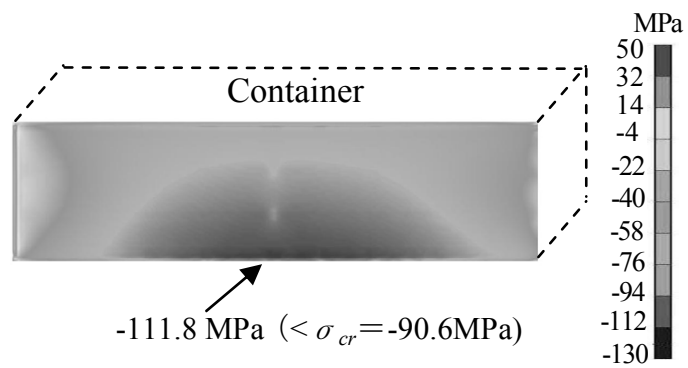

Fig. 19 Longitudinal stress of outer facing of sandwich panel without a slit on Table 5 condition.

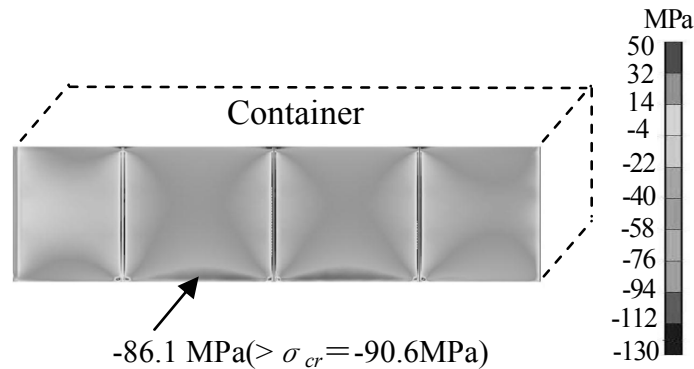

Fig. 20 Longitudinal stress of outer facing of sandwich panel with 3 slits on Table 5 condition.

It was considered that the structure with a slit reduced the thermal stress by deformation of the structure as shown in Fig. 17. However, it was not found that one slit was enough to reduce the thermal stress below the wrinkling strength. Therefore, the containers with some slits were calculated by FEM under the conditions in Table 5.

It has been understood that the generated stress becomes less than the winkling strength by adjusting the slit to three as a result of the calculation. Figure 20 shows the stress distribution of the slit type sandwich panel with three slits. Table 6 shows the result.

\subsection{Mechanisms of stress distribution in the container}

The mechanism of stress distribution as shown in Fig. 12, Table 3 and Fig. 19 was examined as the container was cooled. The bottom of container was considered to be constrained strongly, because the thermal stress was larger by higher constraint. The floor aluminum extrusion shown in Fig. 3 and Table 1 was mounted on bottom of the container. Profile aluminum floor occupied a large proportion of aluminum used in the container. Therefore, it was postulated that the strong restraint was generated in the bottom of the container and the large thermal stress was generated in the lower part of sandwich panel. Then, the thermal stress was calculated in the case of container reducing volume of floor aluminum extrusion by FEM. Figure 21 shows the results. The result of the FEM confirmed a uniformly distributed thermal stress in the container. This shows that the large thermal stress generated in the lower side of a sandwich panel is influenced by volume of floor aluminum extrusion.

\subsection{Strain measurement}

Next, two types of refrigerated containers that had the sandwich panel without a slit and the sandwich panel with three slits were produced as shown in Fig. 22 , and single-axis strain gauges were placed as shown in Fig. 22. 


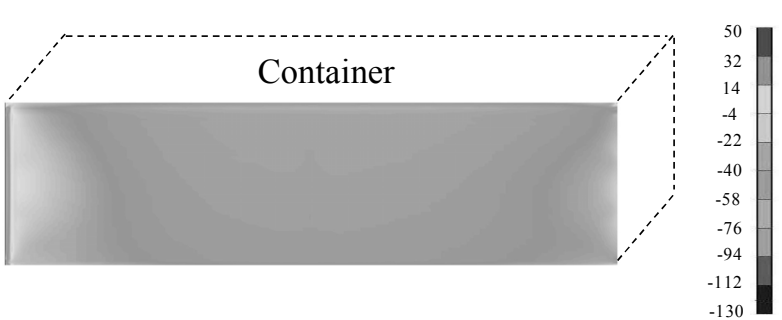

Fig. 21 Longitudinal stress of outer facing of sandwich panel of the container reducing volume of floor aluminum extrusion on Table 5 condition.

Because it was impossible to measure the strain due to the complex setup, the strain based on the condition in Table 7 was measured to calculate the stress for the condition in Table 5 using Eq. (8). However it was preferable to measure directly the strain generated under the condition in Table 5. The strain gauges were zero-balanced just before cooling the inside of refrigerator container.

The stress generated in the outside facing is given by Eq. (9), based on the condition before the inside of the container is cooled.

$$
\begin{aligned}
\sigma_{f_{-} \text {out }} & =\sigma_{\text {def_out }}+\sigma_{\text {fix_out }} \\
& =C_{1} \times \Delta T_{f}+C_{2} \times \Delta T_{\text {out }}
\end{aligned}
$$

$C_{1}$ was calculated from Eq. (9) as $\Delta T_{\text {out }}=0 \mathrm{~K}$ and $\Delta T_{f}=60 \mathrm{~K}$ in Test 1 , and $C_{2}$ was calculated as $T_{f}=0 \mathrm{~K}$ and $\Delta T_{\text {out }}=24 \mathrm{~K}$ in Test 2. Eq. (8) that used $C_{1}$ and $C_{2}$ was confirmed in Test 3.

Table 6 Maximum stress in simulation on Table 5 condition.

\begin{tabular}{|c|c|}
\hline $\begin{array}{c}\text { Maximum stress of non slit panel } \\
{[\mathrm{MPa}]}\end{array}$ & $\begin{array}{c}\text { Maximum stress of } 3 \text { slit panel } \\
{[\mathrm{MPa}]}\end{array}$ \\
\hline$-111.8\left(<\sigma_{c r}=-90.6\right)$ & $-86.1\left(>\sigma_{c r}=-90.6\right)$ \\
\hline
\end{tabular}
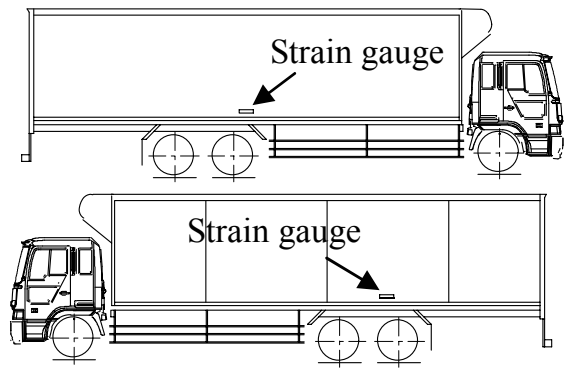

Fig. 22 Refrigerated container for experiment.

Table 7 Experimental condition to evaluate the stress on Table 5 condition.

\begin{tabular}{|c|c|c|c||c|c|}
\cline { 2 - 6 } \multicolumn{1}{c|}{} & $\begin{array}{c}T_{\text {out }} \\
{[\mathrm{K}]}\end{array}$ & $\begin{array}{c}T_{\text {in }} \\
{[\mathrm{K}]}\end{array}$ & $\begin{array}{c}T_{\text {bal }} \\
{[\mathrm{K}]}\end{array}$ & $\begin{array}{c}\Delta T_{f} \\
{[\mathrm{~K}]}\end{array}$ & $\begin{array}{c}\Delta T_{\text {out }} \\
{[\mathrm{K}]}\end{array}$ \\
\hline Test 1 & 303 & 243 & 303 & 60 & 0 \\
\hline Test 2 & 303 & 303 & 279 & 0 & 24 \\
\hline Test 3 & 313 & 243 & 303 & 70 & 10 \\
\hline
\end{tabular}

$T_{b a l}$ : Temperature of outer and inner facings at 0 balance.

$$
\Delta T_{\text {out }}=T_{\text {out }}-T_{\text {bal }}
$$


Table 8 Maximum stress in experiment on Table 7 condition.

\begin{tabular}{|c|c|c|}
\cline { 2 - 3 } \multicolumn{1}{c|}{} & $\begin{array}{c}\text { Maximum stress of } \\
\text { non slit panel } \\
{[\mathrm{MPa}]}\end{array}$ & $\begin{array}{c}\text { Maximum stress of } \\
3 \text { slit panel } \\
{[\mathrm{MPa}]}\end{array}$ \\
\hline Test 1 & -72.1 & -51.8 \\
\hline Test 2 & 5.4 & 7.1 \\
\hline Test 3 & -82.5 & -56.8 \\
\hline
\end{tabular}

Table 9 Maximum stress in experiment on Table 5 condition by using Equations (10) and (11).

\begin{tabular}{|c|c|}
\hline $\begin{array}{c}\text { Maximum stress of } \\
\text { non slit panel } \\
{[\mathrm{MPa}]}\end{array}$ & $\begin{array}{c}\text { Maximum stress of } \\
3 \text { slit panel } \\
{[\mathrm{MPa}]}\end{array}$ \\
\hline$-101.4\left(<\sigma_{c r}=-90.6\right)$ & $-68.8\left(>\sigma_{c r}=-90.6\right)$ \\
\hline
\end{tabular}

Table 10 Comparison between experiment and FEM on Table 5 condition.

\begin{tabular}{|c|c|c|}
\cline { 2 - 3 } \multicolumn{1}{c|}{} & $\begin{array}{c}\text { Maximum stress of } \\
\text { non slit panel } \\
{[\mathrm{MPa}]}\end{array}$ & $\begin{array}{c}\text { Maximum stress of } \\
3 \text { slit panel } \\
{[\mathrm{MPa}]}\end{array}$ \\
\hline FEM & -111.8 & -86.1 \\
\hline Experiment & -101.4 & -68.8 \\
\hline \hline Experiment/FEM & 0.91 & 0.8 \\
\hline
\end{tabular}

\subsection{Test results}

It was confirmed that opening space of the slit became narrower from $6 \mathrm{~mm}$ to $4 \sim 5 \mathrm{~mm}$ by cooling the container and the slit was effective for reducing the thermal stress. Table 8 shows the stress calculated from the strain measured in each panel.

$C_{1}$ and $C_{2}$ in each panel were calculated, and the formula for the computation of $\sigma_{f_{-} \text {out }}$ generated in the outside surface material is as follows from Eq. (8).

$$
\begin{aligned}
\sigma_{\text {non_slit__out }}= & C_{1}\left(T_{\text {out }}-T_{\text {in }}\right)+C_{2}\left(T_{\text {out }}-T_{0}\right) \\
= & \left(\frac{-72.1}{60}\right)\left(T_{\text {out }}-T_{\text {in }}\right) \\
& \quad+\left(\frac{5.4}{24}\right)\left(T_{\text {out }}-T_{0}\right) \\
= & -0.977 T_{\text {out }}-0.225 T_{0}+1.202 T_{\text {in }} \\
\sigma_{3 s \text { sit__out }}= & C_{1}\left(T_{\text {out }}-T_{0}\right)+C_{2}\left(T_{\text {out }}-T_{\text {in }}\right) \\
= & \left(\frac{-51.8}{60}\right)\left(T_{\text {out }}-T_{0}\right) \\
& \quad+\left(\frac{7.1}{24}\right)\left(T_{\text {out }}-T_{\text {in }}\right) \\
= & -0.567 T_{\text {out }}-0.296 T_{0}+0.863 T_{\text {in }}
\end{aligned}
$$


From Eqs. (10) and (11), the generated stresses under $T_{0}=303 \mathrm{~K}$ and the Test 3 condition were calculated as follows.

$$
\begin{aligned}
& \sigma_{\text {non_slit__out_test } 3}=-81.9 \mathrm{MPa} \\
& \sigma_{3 s \text { sit__out_test3 }}=-57.5 \mathrm{MPa}
\end{aligned}
$$

Because these values coincide with Test 3 of Table 8, Eqs. (10) and (11) are useful for calculation of the generated stress in the outer facing. Therefore, the stress generated as listed in Table 5 was calculated by these equations, and Table 9 shows the results.

It is considered from the result in Table 9 that the wrinkling phenomenon is generated in the sandwich panel without a slit and not generated in the sandwich panel with three slits at the temperature conditions listed in Table 5 as well as the FEM result. No wrinkling was generated in the refrigerator container actually produced with the slit type sandwich panel after two years.

\subsection{Comparison between strain measurement result and FEM results}

Table 10 shows the comparison between the experimental results and FEM results. The FEM result almost coincides with the test in the panel without any slit. The reasons why the FEM result is different from the experimental result in the slit type sandwich panel are that (1) the FEM element in the vicinity of the slit part is rough and (2) the joint by rivets is considered between the panel and parts but the contact is not considered. The safety evaluation by using the numerical result and the wrinkling strength is possible by improving the FEM accuracy and noting the above-mentioned point. However, it should be confirmed that the measured thermal stress is below the wrinkling strength, because the correspondence between the FEM results and experimental results might be bad as shown at this time.

\subsection{Wrinkle prevention method in sandwich panel structure}

We propose a method for preventing wrinkling in the sandwich panel structure by having confirmed the method preventing a wrinkle in the refrigerated container according to the following procedures.

(1) The wrinkling strength of the sandwich panel used for the structure is measured by the uni-axial compressive test.

(2) The compressive stress in the length direction of the panel is examined by FEM, and it confirms that it is less than the wrinkling strength. If it is higher than it, the new structure, in which the thermal stress can be reduced and becomes less than the wrinkling strength, is examined by FEM.

(3) The strain is measured in a real structure, and it is confirmed that the stress obtained from the strain is less than the wrinkling strength.

\section{Conclusion}

The failure generated in the aluminum sandwich panel refrigerator container was caused by the wrinkling phenomenon, and the following results were obtained.

(1) The wrinkling strength could be measured by the uni-axial compression test using a small specimen, and not an actual structure, because the wrinkling strength did not depend on the length of the sandwich panel in the compressive direction.

(2) It was confirmed that the sandwich panel with a slit in the facing reduced the thermal stress generated in the sandwich panel structure, and this structure was effective as one of the methods to reduce the thermal stress.

\section{References}

(1) Hoff N.J., Mautner S.E., The buckling of Sandwich-type Panels, Journal of the aeronautical science, Vol.12-7(1945), pp.285-297.

(2) Norris C.B., Ericksen W.S., March H.W., Smith C.B., Boller K.H., Wrinkling of the 
Facings of Sandwich Constructions Subjected to Edgewise Compression, Forest products Laboratory, No.1810(1961).

(3) Uemura M., Stability of Sandwich Construction (in Japanese), Journal of the Japan Society of Mechanical Engineers., Vol.71, No.593(1968), pp.712-720.

(4) Miyairi H., Basic of Sandwich Construction (in Japanese), (1999), pp238-243, Nikkan kougyo shimbun Ltd.

(5) Shimamura S., Miyairi H., Sandwich Construction (in Japanese), (1974), pp163-181, Nikkan kougyo shimbun Ltd.

(6) Nagao H., Stress and Deformation of Heat Resisting Sandwich Plate (in Japanese), Journal of the Japan society of Mechanical Engineers, Vol. 68, No562 (1965), pp.1592-1600.

(7) Bijlaad P.P., Thermal Stresses and Deflections in Rectangular Sandwich Plates, Journal of the Aero/space Sciences, Vol.26-4(1959), pp.210-218.

(8) Timoshenko S., Theory of Plates and Shells, (1940), pp53-54, McGraw-Hill Book Co.

(9) Sanmaru K., Dahara K., Nagata M.,"Refrigerator Container", Japanese Patent Disclosure H19-139388(2007). 